\title{
Regional low-flow perfusion improves neurologic outcome compared with deep hypothermic circulatory arrest in neonatal piglets
}

\author{
Richard J. Myung, MD ${ }^{\mathrm{a}}$ \\ Matus Petko, MD \\ Alexander R. Judkins, MD ${ }^{\mathrm{b}}$ \\ Gregory Schears, MD ${ }^{\mathrm{c}}$ \\ Richard F. Ittenbach, $\mathrm{PhD}^{\mathrm{d}}$ \\ Robert J. Waibel, BS ${ }^{\mathrm{a}}$ \\ William M. DeCampli, MD, PhD
}

From the Division of Cardiothoracic Surgery $^{\mathrm{a}}$ and the Departments of Pathology and Laboratory Medicine, ${ }^{\mathrm{b}}$ Critical Care and Anesthesia, ${ }^{\mathrm{c}}$ and Biostatistics and Epidemiology, ${ }^{d}$ The Children's Hospital of Philadelphia, Philadelphia, Pa.

Supported in part by the Healthcare Foundation of New Jersey.

Read at the Eighty-third Annual Meeting of The American Association for Thoracic Surgery, Boston, Mass, May 4-7, 2003.

Received for publication May 2, 2003; revisions requested Aug 25, 2003; revisions received Nov 4, 2003; accepted for publication Nov 11, 2003

Address for reprints: William M. DeCampli, MD, PhD, Division of Cardiothoracic Surgery, Ste 8527, The Children's Hospital of Philadelphia, 34th and Civic Center Blvd, Philadelphia, PA 19104 (E-mail: decampli@email.chop.edu).

J Thorac Cardiovasc Surg 2004;127:1051-7 $0022-5223 / \$ 30.00$

Copyright $\odot 2004$ by The American Association for Thoracic Surgery

doi:10.1016/j.jtcvs.2003.11.008

Background: Regional low-flow perfusion is an alternative to deep hypothermic circulatory arrest, but whether regional low-flow perfusion improves neurologic outcome after deep hypothermic circulatory arrest in neonates remains unknown. We tested neurologic recovery after regional low-flow perfusion compared with deep hypothermic circulatory arrest in a neonatal piglet model.

Methods: Sixteen neonatal piglets underwent cardiopulmonary bypass, were randomized to 90 minutes of deep hypothermic circulatory arrest or regional low-flow perfusion $\left(10 \mathrm{~mL} \cdot \mathrm{kg}^{-1} \cdot \mathrm{min}^{-1}\right)$ at $18^{\circ} \mathrm{C}$, and survived for 1 week. Standardized neurobehavioral scores were obtained on postoperative days 1,3 , and $7(0=$ no deficit to 90 = brain death). Histopathologic scores were determined on the basis of the percentage of injured and apoptotic neurons in the neocortex and hippocampus by hematoxylin and eosin and terminal deoxynucleotidyl transferase-mediated deoxyuridine triphosphate-biotin nick-end labeling $(0=$ no injury to $4=$ diffuse injury). Differences between groups were tested by using the Wilcoxon rank sum test, and results are listed as medians within a range.

Results: There were no significant differences between groups during cardiopulmonary bypass. Postoperative neurobehavioral scores were abnormal in $25 \%(2 / 8)$ of the regional low-flow perfusion animals versus $88 \%$ (7/8) of controls. Regional low-flow perfusion animals had significantly less neurologic injury compared with controls on postoperative day 1 ( 0.00 [range, $0-5$ ] vs 12.5 [range, $0-52$ ]; $P<.008)$. There was a trend for less severe injury in the regional low-flow perfusion group (2.0 [range, 1-4] vs 0.0 [range, $0-50$ ]; $P=.08$ ) on hematoxylin and eosin. The degree of apoptosis was significantly less in the regional low-flow perfusion group (0.0 [range, $0-1$ ] vs 2.5 [range, $0-4] ; P=.03)$.

Conclusions: Regional low-flow perfusion decreases neuronal injury and improves early postoperative neurologic function after deep hypothermic circulatory arrest in neonatal piglets.

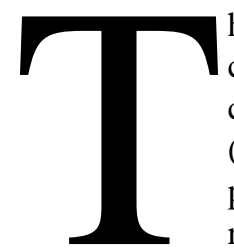
he overall morbidity and mortality of infants undergoing repair of complex congenital heart defects has declined in recent years because of refinements in surgical technique, cardiopulmonary bypass (CPB), and preoperative and postoperative care. However, these patients still remain at risk for both transient and irreversible neurologic injury. Infants undergoing hypothermic $\mathrm{CPB}$ and deep hypothermic circulatory arrest (DHCA) are especially prone to neuropsychiatric insult; 
some authors ${ }^{1}$ report an incidence as high as $25 \%$. Adverse neurologic outcomes include both early postoperative seizures and electroencephalogram abnormalities, in addition to later cognitive impairments such as expressive speech disorders, impaired visual-spatial-motor skills, attentiondeficit/hyperactivity disorder, and other learning disabilities. $^{2,3}$ Although the etiology is probably multifactorial, evidence suggests that both CPB and DHCA may contribute to injury. In particular, DHCA is associated with ischemic/ reperfusion injury and altered cerebral metabolism during recovery, which not only may cause injury but also may predispose the brain to additional insults in the postoperative period. ${ }^{4}$ The exact mechanisms responsible for injury remain to be elucidated. Despite this, some clinicians have implemented alternatives to DHCA, such as low-flow CPB, intermittent $\mathrm{CPB}$, retrograde cerebral perfusion, and antegrade cerebral perfusion.

Recently, several institutions have advocated the use of antegrade regional low-flow perfusion (RLFP). This technique is used at the beginning of DHCA by advancing the aortic cannula into the innominate artery or polytetrafluoroethylene graft, occluding the aortic arch vessels, and maintaining pump flow at a low rate, thereby maintaining brain perfusion while limiting whole-body perfusion. ${ }^{5,6}$ The advantages of RLFP include the use of pump equipment/ cannulas already being used for $\mathrm{CPB}$, the ease of conversion from $\mathrm{CPB}$, the minimization of blood in the surgical field by perfusion of only a relatively small portion of the body, the maintenance of cerebral oxygenation, and the possible mitigation of reperfusion injury. Possible disadvantages include the risk of emboli during cannula manipulation and flow-induced injury. Although several clinical and experimental reports cite the relative benefits of RLFP, whether RLFP prevents neurologic injury in the neonatal brain has not been established. In this study, we hypothesized that RLFP improves neurologic recovery by reduction of neuronal injury compared with DHCA in a neonatal piglet model.

\section{Methods}

\section{Experimental Setup}

Twenty-one 2.1- to 3.2-kg, 2- to 5-day-old neonatal piglets were studied according to a protocol approved by the Institutional Animal Care and Use Committee of the Joseph Stokes Research Institute in compliance with the Guide for the Care and Use of Laboratory Animals prepared by the National Academy of Sciences and published by the National Institutes of Health (National Institutes of Health publication no. 96-03, revised 1996). The animals were anesthetized and mechanically ventilated. Noninvasive monitoring included electrocardiogram, pulse oximetry, blood pressure cuff, and a nasopharyngeal temperature probe. The animals were then randomly assigned to receive $\mathrm{CPB}$ with either DHCA or RLFP.

\section{Surgical Protocol}

Invasive monitoring included an epidural temperature probe placed through a 2-mm burr hole in the temporal region of the skull and an arterial catheter placed into the superficial femoral artery. Animals underwent left thoracotomy, and both arch vessels and descending aorta were dissected out. After heparinization (400 $\mathrm{U} / \mathrm{kg}$ ), the carotid artery and external jugular vein were cannulated with a 14-gauge arterial angiocatheter and a $10 \mathrm{~F}$ venous cannula through a left cervical incision. Those animals undergoing RLFP also received a $5 \mathrm{~F}$ double-lumen catheter introduced into the left carotid in the cephalad direction for both cerebral perfusion and monitoring of cerebral perfusion pressure.

\section{Perfusion and Recovery Protocol}

The CPB circuit consisted of a primary circuit, membrane oxygenator, and arterial filter. A secondary ultrafiltration circuit consisting of a hemofilter perfused with blood from the arterial line of the primary circuit and returned to the venous line. The pump was primed with crystalloid, donor porcine blood $(500 \mathrm{~mL}$ of whole blood), furosemide (1 mg/kg), heparin (1000 U), sodium bicarbonate $(20 \mathrm{mEq}), 25 \%$ human albumin $(60 \mathrm{~mL}), 10 \%$ calcium chloride (1-8 mL), and dexamethasone $(30 \mathrm{mg} / \mathrm{kg})$. After cannulation, the animal was placed on CPB at $100 \mathrm{~mL} \cdot \mathrm{kg}^{-1} \cdot \mathrm{min}^{-1}$. Conventional ultrafiltration via the secondary circuit was used to maintain a prearrest hematocrit between $24 \%$ and $27 \%$. Alpha-stat principles were used for blood gas management. The animal was cooled to a brain temperature of $18^{\circ} \mathrm{C}$ over 20 minutes. At the beginning of the arrest period, the arch vessels and descending aorta were occluded, and cardioplegia consisting of a modified Krebs solution was administered $(20 \mathrm{~mL} / \mathrm{kg})$. Maintenance doses $(10 \mathrm{~mL} / \mathrm{kg}$ ) were given every 30 minutes. The animals remained arrested for 90 minutes. Animals in the RLFP group underwent continuous perfusion $\left(10 \mathrm{~mL} \cdot \mathrm{kg}^{-1} \cdot \mathrm{min}^{-1}\right)$. After DHCA, the animals were rewarmed to at least $33^{\circ} \mathrm{C}$ over 30 minutes. Mannitol $\left(125 \mathrm{mg} / \mathrm{kg}\right.$ ) was administered at $27^{\circ} \mathrm{C}$. The heart was defibrillated as necessary. After rewarming, the animals were weaned from CPB and underwent 15 minutes of modified ultrafiltration via the secondary bypass circuit. Modified ultrafiltration was maintained at a rate of $30 \mathrm{~mL} \cdot \mathrm{kg}^{-1} \cdot \mathrm{min}^{-1}$ and a mean blood pressure of 40 to $50 \mathrm{~mm} \mathrm{Hg}$. After extubation, animals were placed into an oxygenated incubator (oxygen $4 \mathrm{~L} / \mathrm{min}$ ) for at least 24 hours until they could tolerate room air with normal saturations. Animals that required postoperative hydration received either crystalloid solution intravenously or tube feeding of milk-replacement formula.

\section{Neurologic Assessment}

The neurobehavioral score was determined on postoperative days 1,3 , and 7 by a trained observer blinded to group assignment. The neurologic performance score is based on both behavioral and neurologic examination and ranges from 0 (no deficit) to 90 (brain death), as shown in Table $1 .{ }^{7}$ On postoperative day 7 , the animals were killed, and the cortex was perfused with $1 \mathrm{~L}$ of saline followed by $1 \mathrm{~L}$ of $4 \%$ paraformaldehyde at $4^{\circ} \mathrm{C}$. The brain was removed in toto, placed in $4 \%$ paraformaldehyde for 4 hours, and then transferred to phosphate-buffered saline. Because our previous study had shown that both hemispheres were comparably perfused by unilateral carotid perfusion at the currently used RLFP rates, the left hemisphere was cut in 5-mm coronal sections, 
TABLE 1. Neurobehavioral score

\begin{tabular}{lc}
\hline Variable & Score \\
\hline Level of consciousness & \\
Normal & 0 \\
Clouded & 5 \\
Stuporous & 12 \\
Comatose & 25 \\
Cranial nerves & \\
Vision absent & 1 \\
Light reflex absent L/R & $0.5 / 0.5$ \\
Corneal reflex absent L/R & $0.5 / 0.5$ \\
Facial sensation absent & 1 \\
Auditory absent & 1 \\
Gag reflex absent & 1 \\
Motor/sensory function & \\
Flexor response to pain UE L/R & $1 / 1$ \\
Flexor response to pain LE L/R & $1 / 1$ \\
Righting reflex absent & 10 \\
Gait & \\
Normal & 0 \\
Minimal ataxia & 5 \\
Moderate ataxia & 10 \\
Able to stand only & 15 \\
Unable to stand & 20 \\
No purposeful movement & 25 \\
Behavior & \\
Not drinking & 10 \\
Not exploring & 10 \\
\hline
\end{tabular}

$L$, Left; $R$, right; $U E$, upper extremity; $L E$, lower extremity.

${ }^{*} 0=$ normal; $90=$ brain death

processed, and embedded in paraffin. ${ }^{8}$ Five-micrometer sections were cut from blocks and mounted onto slides.

Histologic injury was assessed by using routine and apoptosisspecific staining. Although several areas of the brain, including the deep central gray matter and basal ganglia, are susceptible to ischemic injury, the hippocampus and neocortex have been shown to demonstrate the most neuronal injury 1 week after DHCA in neonatal piglets. ${ }^{9}$ Specifically, the CA1 to CA4 regions of the hippocampus and all layers of the neocortex were examined by a neuropathologist blinded to group assignment. Routine staining consisted of hematoxylin and eosin (H\&E). Neuronal damage was identified by changes indicative of neuronal injury, including 1 or more of the following: hyperchromatic and shrunken nuclei, cytoplasmic eosinophilia, and karyorrhectic nuclei. Apoptosis via DNA fragmentation was detected by using the terminal deoxynucleotidyl transferase-mediated deoxyuridine triphosphate-biotin nick-end labeling (TUNEL) technique with a commercially available kit (In Situ Cell Death Kit; Roche, Indianapolis, Ind). Positive controls (piglet thymus tissue) and negative controls (without terminal deoxynucleotidyl transferase) were performed with each assay. Histopathologic scores were determined on the basis of a semiquantitative analysis of the relative percentage of damaged neurons: $0=$ no damage to $4=$ diffuse damage (Table 2). Each section received a separate score for the cortex and hippocampus, which then determined an overall score for both H\&E and TUNEL sections.

\section{TABLE 2. Neurohistologic score}

\begin{tabular}{lc}
\hline Criteria & Score \\
\hline Normal; no injury or rare isolated apoptotic neuron & 0 \\
Rare neuronal injury $(<5$ clusters) & 1 \\
Occasional neuronal injury (5-15 clusters) & 2 \\
Frequent neuronal injury ( $>15$ clusters) & 3 \\
Diffuse neuronal injury & 4
\end{tabular}

\author{
Statistical Analysis \\ Differences between the treatment (RLFP) and control (DHCA) \\ groups were tested by using the Wilcoxon rank sum test. The \\ experimentwise error rate for the study was held constant at the \\ $\alpha=.05$ level across all 5 comparisons, with each of the 5 tests \\ conducted at the adjusted $\alpha=.02$ level using the algorithm of \\ Tukey, Ciminera, and Heyse for adjustments of multiple, highly \\ correlated comparisons. ${ }^{10}$
}

\section{Results}

All 21 animals completed the surgical protocol without technical complications. Four of 12 animals in the DHCA group and 1 of 9 animals in the RLFP group died between postoperative days 0 and 3 . Because the degree of neuronal injury could have been influenced by the cause of death and because the cause of death could not be determined in these animals, they were excluded from the study. In the remaining 16 animals, there were no significant differences in preoperative body weight (DHCA, $2.57 \pm 0.30 \mathrm{~kg}$; RLFP, $2.61 \pm 0.33 \mathrm{~kg}$ ), and there were no preoperative neurobehavioral deficits. During the surgical protocol, no significant differences existed between groups in arterial blood gases, hematocrit, brain temperatures, glucose, hemodynamics, or duration between phases of bypass (Table 3 ).

Both groups showed neurobehavioral deficits after recovery. On postoperative day 1 , however, the RLFP group neurobehavioral scores were significantly better than those of the DHCA group, with a median score of 0.0 (range, 0-5) versus 12.5 (range, $0-52)$ in the DHCA group $(P<.01)$. The scores were not statistically different on postoperative days 3 and 7 . Specifically, only $2(25 \%)$ of 8 animals in the RLFP group demonstrated detectable neurologic injury, which consisted of minimal ataxia on postoperative day 1 . In both cases, deficits resolved by postoperative day 3 . The remaining RLFP animals showed no deficits on any postoperative day. In contrast, 87.5\% (7/8) of the DHCA group demonstrated neurologic impairments. Deficits in the DHCA group varied on postoperative day 1 from no deficit in 1 animal to a clouded level of consciousness and inability to stand in the most severely injured animal. Most deficits were composed of clouded consciousness, ataxia, and failure to drink or explore. In this group, the deficits resolved by postoperative day 7 , except for the most severely affected animal. 
TABLE 3. Cardiopulmonary bypass data for DHCA and RLFP groups $(n=16)$

\begin{tabular}{|c|c|c|c|c|c|}
\hline Variable & Before bypass & $\begin{array}{l}\text { Prearrest cooling } \\
\left(19^{\circ} \mathrm{C}\right)\end{array}$ & $\begin{array}{c}\text { RLFP/DHCA } \\
\left(18^{\circ} \mathrm{C}\right)\end{array}$ & Rewarming $\left(25^{\circ} \mathrm{C}\right)$ & Recovery \\
\hline \multicolumn{6}{|l|}{$\mathrm{pH}$} \\
\hline DHCA & $7.57 \pm 0.10$ & $7.35 \pm 0.06$ & & $7.38 \pm 0.08$ & $7.40 \pm 0.09$ \\
\hline RLFP & $7.59 \pm 0.13$ & $7.34 \pm 0.09$ & $7.48 \pm 0.07$ & $7.44 \pm 0.07$ & $7.44 \pm 0.16$ \\
\hline \multicolumn{6}{|l|}{ Oxygen } \\
\hline DHCA & $526.7 \pm 69.5$ & $384.2 \pm 55.9$ & & $277.0 \pm 19.8$ & $582.7 \pm 69.4$ \\
\hline RLFP & $465.3 \pm 132$ & $356.4 \pm 39.5$ & $263.4 \pm 36.8$ & $202.4 \pm 50.0$ & $498.3 \pm 104.4$ \\
\hline \multicolumn{6}{|l|}{$\mathrm{CO}_{2}$} \\
\hline DHCA & $29.21 \pm 6.04$ & $50.94 \pm 8.13$ & & $37.35 \pm 8.63$ & $37.42 \pm 8.57$ \\
\hline RLFP & $28.75 \pm 9.85$ & $49.75 \pm 7.91$ & $34.0 \pm 1.5$ & $34.38 \pm 7.61$ & $40.25 \pm 14.97$ \\
\hline \multicolumn{6}{|l|}{$\mathrm{HCO}_{3}$} \\
\hline DHCA & $26.09 \pm 5.65$ & $28.16 \pm 3.62$ & & $21.44 \pm 2.40$ & $23.15 \pm 5.43$ \\
\hline RLFP & $26.94 \pm 3.43$ & $26.55 \pm 3.31$ & $25.2 \pm 1.2$ & $22.74 \pm 4.27$ & $27.50 \pm 7.96$ \\
\hline \multicolumn{6}{|c|}{ Arterial pressure $(\mathrm{mm} \mathrm{Hg})$} \\
\hline DHCA & $49.38 \pm 8.94$ & $37.38 \pm 6.84$ & & $32.13 \pm 6.64$ & $55.63 \pm 4.53$ \\
\hline RLFP & $46.50 \pm 6.16$ & $33.00 \pm 9.80$ & $\begin{array}{c}26.3 \pm 0.3 \\
\text { (carotid) }\end{array}$ & $32.13 \pm 6.77$ & $50.88 \pm 6.10$ \\
\hline \multicolumn{6}{|c|}{ Brain temperature $\left({ }^{\circ} \mathrm{C}\right)$} \\
\hline DHCA & $34.38 \pm 0.92$ & $18.75 \pm 0.46$ & & $24.13 \pm 3.36$ & $33.63 \pm 0.92$ \\
\hline RLFP & $34.26 \pm 2.21$ & $18.25 \pm 1.04$ & $17.8 \pm 0.1$ & $24.38 \pm 2.97$ & $33.75 \pm 0.46$ \\
\hline \multicolumn{6}{|c|}{ Hematocrit (\%) } \\
\hline DHCA & $27.63 \pm 4.96$ & $24.38 \pm 2.20$ & & $20.00 \pm 4.66$ & $38.33 \pm 7.69$ \\
\hline RLFP & $26.13 \pm 3.00$ & $25.13 \pm 3.44$ & $21.8 \pm 1.2$ & $21.75 \pm 4.13$ & $32.71 \pm 4.03$ \\
\hline
\end{tabular}

Results are expressed as mean \pm SD. DHCA, Deep hypothermic circulatory arrest; RLFP, regional low-flow perfusion.

Histopathologic injury by H\&E staining was present in both groups. Injured neurons appeared either with karyorrhectic nuclei, as an intensely eosinophilic "dead red neuron," or with necrosis. In general, damaged neurons in the neocortex appeared in isolated clusters of cells in the deep layers of the gray matter (layers 4 and 5), interspersed between normal cells equally distributed throughout the hemisphere. Neuronal injury in the hippocampus was seen in all sectors (CA1-4) to a variable degree and consisted mostly of dead red neurons in the pyramidal cell layer. The pattern of injury was similar in both groups and was present in all animals, with a median of 2.0 (range, 1-4) in the RLFP group and 3.5 (range, $1-4)$ in the DHCA group $(P=.08)$.

Neuronal injury by TUNEL staining was also present in both groups. TUNEL-positive neurons generally mirrored the location of necrotic neuronal injury seen on H\&E sections. In contrast to necrotic neuronal injury, TUNEL-positive cells were generally observed as isolated cells interspersed among normal neurons; diffuse clusters of TUNELpositive cells were present in only the most severely injured animals. Again, in the hippocampus, the most injury occurred in a sparse distribution along the pyramidal cell layer except for the most severely injured animals. Overall, significant apoptosis was demonstrated in $37.5 \%$ of animals receiving RLFP (3/8) compared with $87.5 \%$ (7/8) in the DHCA group. The degree of apoptosis was significantly less in the RLFP group, with a median of 0.0 (range, 0-1) in the RLFP group and 2.5 (range, $0-4)$ in the DHCA group $(P=$
.03). Table 4 summarizes the results for neurobehavioral, histopathologic, and apoptotic scores.

\section{Discussion}

Despite the instrumental role of DHCA in the success of congenital heart surgery, DHCA has been the focus, in recent years, of increasing concern regarding its long-term neurologic sequelae. The exact mechanism for neurologic injury remains unknown, but the degree of injury likely stems from patient-specific factors coupled with perioperative environmental influences such as the type of support used during operation (DHCA or continuous CPB), use of hemodilution, degree of cooling, type of blood gas management, and independent patient factors. ${ }^{11,12}$ Although DHCA provides a bloodless surgical field, facilitating surgical repair and decreasing the duration of blood exposure to the bypass circuit, most clinicians would agree that minimizing the duration of DHCA would be beneficial.

Many therapeutic interventions have been proposed to prevent or minimize neurologic injury during DHCA, with promising early results. Specifically, antegrade RLFP mitigates the need for DHCA while minimizing the exposure of the entire body to significant flows of CPB. Swain and colleagues $^{13}$ determined that flows as low as $10 \mathrm{~mL} \cdot \mathrm{kg}^{-1}$ - $\min ^{-1}$ were adequate to maintain cerebral high-energy phosphates during low-flow CPB. Later, Asou and colleagues ${ }^{5}$ described a modification of a low-flow CPB technique with either direct cannulation of the innominate artery 
or cannulation of the tetrafluoroethylene graft and snaring of the aortic arch vessels during aortic arch repairs. By either method, regional perfusion is obtained by an easy conversion from CPB and provides a relatively bloodless field. Pigula and associates ${ }^{14}$ demonstrated that both the cerebral blood volume index and cerebral oxygen saturation measured by near-infrared spectroscopy could be maintained to prebypass levels by using this technique. The same authors reported evidence that RLFP could provide somatic circulatory support. ${ }^{15}$ To date, several clinical studies not only have demonstrated the feasibility of maintaining cerebral oxygenation, but also have shown that RLFP was associated with no early clinically evident adverse neurologic events. ${ }^{14,16,17}$

With these promising clinical results, we began an initial effort to understand the physiology and mechanisms of RLFP by using a modification of a well-described animal model of DHCA. In a previous experiment, we used oxygen-dependent phosphorimetry to illustrate that microvascular oxygen tension (the oxygen available at the tissue level in the cortex) is maintained by RLFP and in fact improved during recovery in a piglet model of DHCA. ${ }^{8}$ It is interesting to note that improved recovery applied only to moderate levels of flow $\left(20 \mathrm{~mL} \cdot \mathrm{kg}^{-1} \cdot \mathrm{min}^{-1}\right)$, whereas higher levels of flow $\left(40 \mathrm{~mL} \cdot \mathrm{kg}^{-1} \cdot \mathrm{min}^{-1}\right)$ were detrimental. With these initial physiologic results, we undertook this study to discover whether RLFP offers an improvement in neurologic recovery compared with DHCA in neonates.

The findings in this study support the hypothesis that RLFP decreases neuronal injury and improves early postoperative neurologic function compared with DHCA in neonatal piglets. The patterns of histologic injury and neurologic recovery seen in our DHCA control group were similar to those found by other investigators. In contrast to the consistent neurologic injury seen in DHCA animals, postoperative neurologic recovery in animals receiving RLFP was significantly better than in controls on postoperative day 1. It is interesting to note that there were no statistically significant differences in the degree of neuronal injury as demonstrated by the $H \& E$ stains, as opposed to the TUNEL stain. This discrepancy could be due to several possible etiologies. First, the degree of necrosis may be influenced by CPB and hypothermia, in addition to DHCA, to which both groups were equally subjected. For example, microembolic phenomena may have occurred during any phase of CPB (including RLFP), causing neuronal injury indistinguishable from injury sustained during DHCA by postoperative day 7. Second, it is possible that, although RLFP and DHCA produce similar degrees of cellular necrosis, DHCA and subsequent reperfusion may be a relatively stronger stimulus of apoptosis compared with RLFP. Third, it is possible that we were not using the optimal conditions for RLFP.
TABLE 4. Significance tests for neurobehavioral, H\&E, and TUNEL scores $(\mathbf{n}=\mathbf{1 6})$

\begin{tabular}{lccr}
\hline Measure & $\begin{array}{c}\text { DHCA, median } \\
\text { (range) }(\boldsymbol{n}=\mathbf{8})\end{array}$ & $\begin{array}{c}\text { RLFP, median } \\
\text { (range) }(\boldsymbol{n}=\mathbf{8})\end{array}$ & $\boldsymbol{P}$ value \\
\hline Neurobehavioral score & & & \\
$\quad$ Day 1 & $12.5(0-52)$ & $0.0(0-5)$ & $<.01$ \\
Day 3 & $0.0(0-50)$ & $0.0(0-0)$ & .08 \\
Day 7 & $0.0(0-15)$ & $0.0(0-0)$ & .38 \\
H\&E score & $3.5(1-4)$ & $2.0(1-4)$ & .08 \\
TUNEL score & $2.5(0-4)$ & $0.0(0-1)$ & .03 \\
\hline
\end{tabular}

$H \& E$, Hematoxylin and eosin; RLFP, regional low-flow perfusion; DHCA, deep hypothermic circulatory arrest; TUNEL, terminal deoxynucleotidyl transferase-mediated deoxyuridine triphosphate-biotin nick-end labeling.

In fact, the optimal conditions for the conduct of RLFP in terms of cerebral vascular resistance and its effects on flow rate and pressure remain to be determined. Cerebral vascular resistance can be manipulated with the use of vasodilators or gas management strategies. Alpha-stat was used in this study during cooling, RLFP (or DHCA), and rewarming because this is the primary blood gas strategy at our institution and in some recent clinical studies of RLFP. However, in DHCA, a pH-stat strategy used during cooling has been shown to provide a protective effect. The relative acidosis of the pH-stat strategy increases cerebral blood flow and oxygen-hemoglobin dissociation, decreases oxygen demand, and improves cerebral cooling. ${ }^{18,19}$ Using $\mathrm{pH}$ stat during RLFP, however, implies the use of higher flow rates to maintain adequate cerebral oxygenation that may cause flow-induced injury. Thus, the superiority of one $\mathrm{CO}_{2}$ strategy over the other with RLFP remains unclear.

Even within the use of a single gas strategy, the optimal flow rate remains unclear. In this study, we chose an RLFP flow rate of $10 \mathrm{~mL} \cdot \mathrm{kg}^{-1} \cdot \mathrm{min}^{-1}$ with a perfusion pressure of $26 \pm 0.3 \mathrm{~mm} \mathrm{Hg}$. We chose this flow rate because it approximated the perfusion pressure that maintained cerebral microvascular oxygen tension in our previous experiment with a flow rate of $20 \mathrm{~mL} \cdot \mathrm{kg}^{-1} \cdot \mathrm{min}^{-1}$ through the innominate artery with alpha-stat principles. ${ }^{8}$ Clinically, the indecision regarding flow strategy is apparent; a broad range of flow rates are reported from 10 to $100 \mathrm{~mL} \cdot \mathrm{kg}^{-1}$. $\min ^{-1} \cdot{ }^{14,20,21}$ Measurement of cerebral blood volume and relative oxygen saturation by using near-infrared spectroscopy or of cerebral blood flow by using transcranial Doppler imaging may provide some guidance for optimizing RLFP flow rates, but its accuracy in this setting has yet to be determined by either laboratory or clinical studies.

In addition, the mechanisms of apoptotic neuronal death are poorly understood. Our study and others have demonstrated apoptosis occurring within several days after DHCA. ${ }^{22-24}$ What remain to be determined are the exact mechanisms after DHCA that initiate apoptosis, possible 
therapeutic interventions, and even the role of RLFP in delivering apoptotic inhibitors.

The experimental design of this study has some limitations. As previously described, a 90-minute circulatory arrest time was used. Although this duration of DHCA may be longer than the average reported duration of DHCA in clinical settings, in other studies that used this animal model, an extended period of arrest was necessary to produce a consistent and reproducible level of neuronal injury. ${ }^{9,18,23,24}$ Clinically, differences between RLFP and DHCA may not be readily pronounced, as this study suggests. Also, we analyzed only 1 time point in the course of neurologic recovery and thus could not quantitate the complex role of the cortical remodeling and white matter injury that occurs after cerebral insult as the brain matures. Finally, we did not specifically measure the time-dependent removal of apoptotic cell remnants. Although apoptotic cell density peaks at approximately 72 hours after ischemic injury, substantial fractions of apoptotic cells remain at 7 days. In this model, we assumed that the measured degree of apoptosis at 7 days was proportional to the peak apoptotic activity in both groups. This assumption has yet to be proven.

\section{Conclusion}

Despite advances in congenital heart surgery, infants subjected to DHCA remain at risk for poor neurologic outcome. RLFP is a promising neuroprotective strategy. This study suggests that RLFP improves neurologic recovery and attenuates apoptotic neuronal death as compared with DHCA. However, the optimal conditions for regional low-flow bypass remain to be determined.

\section{References}

1. Ferry PC. Neurologic sequelae of open-heart surgery in children. Am J Dis Child. 1990;144:369-73.

2. Hickey PR. Neurologic sequelae associated with deep hypothermic circulatory arrest. Ann Thorac Surg. 1998;65:65-70.

3. Wernovsky G, Jonas RA, Hickey PR, du Plessis AJ, Newburger JW. Clinical neurologic and developmental studies after cardiac surgery utilizing hypothermic circulatory arrest and cardiopulmonary bypass. Cardiol Young. 1993;3:308-16.

4. Greeley WJ, Kern FH, Meliones JN, Ungerleider RM. Effect of deep hypothermia and circulatory arrest on cerebral blood flow and metabolism. Ann Thorac Surg. 1993;56:1464-6.

5. Asou T, Kado H, Imoto Y, Shiokawa Y, Tominaga R, Kawachi Y, et al. Selective cerebral perfusion technique during aortic arch repair in neonates. Ann Thorac Surg. 1996;61:1546-8.

6. Imoto Y, Kado H, Shiokawa Y, Fukae K, Yasui H. Norwood procedure without circulatory arrest. Ann Thorac Surg. 1999;68:559-61.

7. Reasoner DK, Hindman BJ, Dexter F, Subieta A, Cutkomp J, Smith T. Doxycycline reduces early neurologic impairment after cerebral arterial air embolism in the rabbit. Anesthesiology. 1997;87:569-76.

8. DeCampli WM, Schears G, Myung RJ, Schultz S, Creed J, Pastuszko A, et al. Tissue oxygen tension during regional low-flow perfusion in neonates. J Thorac Cardiovasc Surg. 2003;125:472-80.

9. Kurth CD, Priestley M, Golden J, McCann J, Raghupathi R. Regional patterns of neuronal death after deep hypothermic circulatory arrest in newborn pigs. J Thorac Cardiovasc Surg. 1999;118:1068-77.

10. Zhang J, Quan H, Ng J, Stepanavage ME. Some statistical methods for multiple endpoints in clinical trials. Control Clin Trials. 1997;18:20421.

11. duPlessis AJ. Mechanisms of brain injury during infant cardiac surgery. Semin Pediatr Neurol. 1999;6:32-47.

12. Newburger JW, Jonas RA, Wernovsky G, Wypij D, Hickey PR, Kuban $\mathrm{KC}$, et al. A comparison of the perioperative neurologic effects of hypothermic circulatory arrest versus low-flow cardiopulmonary bypass in infant heart surgery. $N$ Engl J Med. 1993;329:1057-64.

13. Swain JA, McDonald TJ, Griffith PK, Balaban RS, Clark RE, Ceckler TL. Low-flow hypothermic cardiopulmonary bypass protects the brain. J Thorac Cardiovasc Surg. 1991;102:76-83.

14. Pigula FA, Nemoto EM, Griffith BP, Siewers RD. Regional low-flow perfusion provides cerebral circulatory support during neonatal aortic arch reconstruction. J Thorac Cardiovasc Surg. 2000;119:331-9.

15. Pigula FA, Gandhi SK, Siewers RD, Davis PJ, Webber SA, Nemoto EM. Regional low-flow perfusion provides somatic circulatory support during neonatal aortic arch surgery. Ann Thorac Surg. 2001;72:401-7.

16. Yamashita K, Kazui T, Terada H, Washiyama N, Suzuki K, Bashar A. Cerebral oxygen monitoring for total arch replacement using selective cerebral perfusion. Ann Thorac Surg. 2001;72:503-8.

17. Lim C, Kim WH, Kim SC, Rhyu JW, Baek MJ, Oh SS, et al. Aortic arch reconstruction using regional perfusion without circulatory arrest. Eur J Cardiothorac Surg. 2003;23:149-55.

18. Priestley MA, Golden JA, O'Hara IB, McCann J, Kurth CD. Comparison of neurologic outcome after deep hypothermic circulatory arrest with alpha-stat and $\mathrm{pH}$-stat cardiopulmonary bypass in newborn pigs. J Thorac Cardiovasc Surg. 2001;121:336-43.

19. Bellinger DC, Wypij D, du Plessis AJ, Rappaport LA, Riviello J, Jonas RA, et al. Developmental and neurologic effects of alpha-stat versus $\mathrm{pH}$-stat strategies for deep hypothermic cardiopulmonary bypass in infants. J Thorac Cardiovasc Surg. 2001;121:374-83.

20. Lim C, Kim WH, Kim SC, Rhyu JW, Baek MJ, Oh SS, et al. Aortic arch reconstruction using regional perfusion without circulatory arrest. Eur J Cardiothorac Surg. 2003;23:149-55.

21. Cooper WA, Duarte IG, Thourani VH, Nakamura M, Wang NP, Brown WM, et al. Hypothermic circulatory arrest causes multisystem vascular endothelial dysfunction and apoptosis. Ann Thorac Surg. 2000;69:696-702.

22. Kin H, Isibashi K, Mitatori T, Kawazoe K. Hippocampal neuronal death following deep hypothermic circulatory arrest in dogs: involvement of apoptosis. Cardiovasc Surg. 1999;7:558-64.

23. Ditsworth D, Priestley MA, Loepke AW, Ramamoorthy C, McCann J, Staple L, et al. Apoptotic neuronal death following deep hypothermic circulatory arrest in piglets. Anesthesiology. 2003;98:1039-41.

24. Myung RJ, Kirshbom PM, Petko M, Golden JA, Judkins AR, Ittenbach $\mathrm{RF}$, et al. Modified ultrafiltration may not improve neurologic outcome following deep hypothermic circulatory arrest. Eur J Cardiothorac Surg. 2003;24:243-8.

\section{Discussion}

Dr Jason S. Sperling (Charlottesville, $\mathrm{Va}$ ). Did you expect any deaths of the piglets in the circulatory arrest group? I think I noticed there were more in the circulatory arrest group than the low-flow perfusion group; how do you think that affected your interpretation of your results?

Dr Myung. Since we used a chronic animal model, we did expect some attrition. In a previous study using 90 minutes of circulatory arrest, we had an attrition rate below $20 \%$. The much higher attrition rate in the arrest group in this study was not expected. However, I do not believe this affected our interpretation of the results, since we did not use survival between groups as a measure of outcome and only 7-day survivors were included in the analysis.

Dr W. Randolph Chitwood, Jr (Greenville, NC). How is this different from in adults?

Dr Myung. There are some data suggesting that, at least in the neonatal piglet brain, there is a rapid and large amount of cortical 
remodeling. Whereas regional low-flow perfusion in adults is not as promising, the degree of remodeling and the amount of injury that the neonatal brain can sustain make this and other neuroprotective interventions more promising in neonates.

Dr Chitwood. Do you think it is species specific?

Dr Myung. Yes, there is that possibility. The neonatal piglet is less susceptible to ischemic and reperfusion injury, given the fact that they can survive 90 minutes of circulatory arrest, and at least certain animals sustain no detectable neurologic injury whatsoever.

Dr Chitwood. Obviously the pigs cannot talk and think and be depressed. And I guess they are, but we do not get the chance to really discuss it with them.

You have shown some pretty interesting data. So low-flow hypothermia is much better? Do you think it is totally protective?

Dr Myung. It is not totally protective, because there was low-level neurologic injury even in the regional low-flow perfusion group.

What is significant in this study is that the amount of apoptotic injury was significantly less. While the mechanisms of neuronal injury remain poorly understood, it is likely that animals subjected to deep hypothermic circulatory arrest may be more prone to apoptotic injury triggered by ischemia and reperfusion.

Dr Jakob Vinten-Johansen (Atlanta, Ga). Have you used microspheres to look at the distribution of flow in the brain? Is it homogeneous within all areas of the brain?

Dr Myung. No, we have not done a microsphere study. But we did do a previous study looking at microvascular oxygen tension and showed that generally all areas of the cortices were well perfused at both 20 and $40 \mathrm{~mL} \cdot \mathrm{kg}^{-1} \cdot \mathrm{min}^{-1}$.

Dr Vinten-Johansen. What mechanisms do you think are involved in the avoidance of injury? Is the mechanism a simple providing of oxygen? Is it avoiding oxygen radical generation? Is it avoiding the inflammatory response and neutrophil-mediated injury? Do you have any idea?

Dr Myung. We did not investigate the mechanisms of injury in this study, but we suspect that the degree of ischemia and reperfusion injury, which is a well-known pathway of injury, is attenuated by using regional low-flow perfusion.

Dr Y. Joseph Woo (Philadelphia, Pa). As you mentioned, it is sort of interesting that you have extensive necrosis and apoptosis pathways going on here, and I was interested in whether or not you had any insights, perhaps not in these studies, but just in general, as to the timing of your apoptosis pathways. Did you look at bcl-2 levels or any of the other caspase activations or anything? Is this something that is happening later on, or is this all related?

Dr Myung. Dr Kurth and colleagues from our institution did a study looking at the actual time progression of necrotic and apoptotic injury. It is obvious that a large wave of necrosis and apoptosis will follow after the initial insult, but they showed that apoptotic injury was sustained for at least 7 days after the surgery.
To answer your second question, we are just beginning to look at caspase expression and activation in this model, but we do not have any results yet.

Dr Gerald D. Buckberg (Los Angeles, Calif). It is a very interesting study relating to the fact that if you are going to have a brain without a blood supply, perfusion is better than ischemia at the same temperatures.

I am intrigued with the apoptosis on a couple of levels. These are healthy animals, and I think that gives you a little bit of a vision of what would happen if this were an unhealthy animal vis-à-vis somebody after bypass who had hemodynamic instability. It is possible that you might accelerate the damage. And you are looking at a cell that is potentially going to die, and you might comment or speculate on what would happen if you added on more injury from inadequate cardiac output, or have you separated some of these studies to see in animals that had some hemodynamic instability if that was a worse lesion?

Dr Myung. We didn't look into other factors that may predispose the animal to apoptotic injury, but certainly postoperative factors can contribute significantly to neurologic injury. Especially in the neonatal population, cyanosis may predispose the infant to apoptotic injury, and no one has looked at that yet.

Dr Jian Ye (Winnipeg, Manitoba, Canada). I have a question regarding technique. Basically low-flow sounds like antegrade cerebral perfusion, so you control the flow at the $10 \mathrm{~mL} \cdot \mathrm{kg}^{-1}$. $\min ^{-1}$, and did you measure the pressure?

Dr Myung. Yes, we did use antegrade perfusion and measured the pressure. The perfusion pressure was $26 \mathrm{~mm} \mathrm{Hg}$ at $10 \mathrm{~mL}$. $\mathrm{kg}^{-1} \cdot \min ^{-1}$.

We chose that flow rate for several reasons. Swain and colleagues showed that, in the setting of low-flow bypass, $10 \mathrm{~mL}$. $\mathrm{kg}^{-1} \cdot \min ^{-1}$ was sufficient to maintain high-energy phosphates in the brain. In a subsequent study, we showed that with innominate artery perfusion, $20 \mathrm{~mL} \cdot \mathrm{kg}^{-1} \cdot \mathrm{min}^{-1}$ maintained microvascular oxygen tension in the brain. In the current study, since we were perfusing a single carotid, we believed that $10 \mathrm{~mL} \cdot \mathrm{kg}^{-1} \cdot \mathrm{min}^{-1}$ would be adequate, and that resulted in a perfusion pressure of 26 $\mathrm{mm} \mathrm{Hg}$, which was nearly equivalent to the perfusion pressure from our previous study.

Dr Ye. Did you clamp the right side of the carotid artery?

Dr Myung. We clamped the aortic arch vessels, which in a pig would be the innominate and left subclavian arteries, so just about everything that we were perfusing through the left carotid was going into the brain.

Dr Ye. You did say that in the low-flow circulatory arrest group, you had 4 piglets that actually died between day 0 and day 3. How many animals reached day 7? That is including your neurologic assessment.

Dr Myung. We had 16 survivors through the entire week to day 7,8 survivors in each group. 